\title{
Correlating Interlayer Spacing and Separation Capability of Graphene Oxide Membranes in Organic Solvents
}

\section{Supporting Information}

Sunxiang Zheng ${ }^{\mathrm{a}}$, Qingsong Tu${ }^{\mathrm{a}}$, Monong Wang ${ }^{\mathrm{a}}$, Jeffrey J. Urban ${ }^{\mathrm{b}}$, Baoxia $\mathrm{Mi}^{\mathrm{a}^{*}}$

${ }^{a}$ Department of Civil and Environmental Engineering

University of California

Berkeley, CA 94720

${ }^{b}$ The Molecular Foundry

Materials Sciences Division

Lawrence Berkeley National Laboratory

Berkeley, CA 94720

Number of pages: 12

Number of figures: 12

Number of tables: 2

* The author to whom correspondence should be addressed. E-mail: mib@berkeley.edu; Tel.: (510) 664-7446. 


\section{Size Distribution of GO Nanosheets}

The size distribution of the as-synthesized GO nanosheets was characterized by Dynamic Light Scattering (DLS) analysis. A single peak at around $800 \mathrm{~nm}$ can be observed.

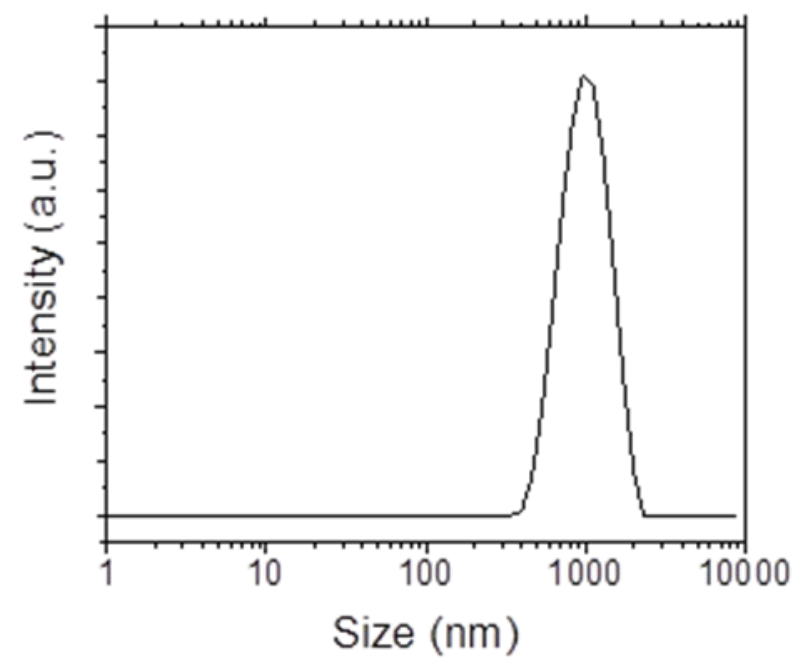

Figure S1. Size distribution of GO nanosheets.

\section{Oxidation Degree of GO Nanosheets}

The oxidation degree of GO nanosheets was characterized by XPS. Based on the XPS survey spectrum of a dry GO film (Figure $\mathrm{S} 1$ ), the oxygen/carbon $(\mathrm{O} / \mathrm{C})$ ratio can be calculated as $28.8 \% / 71.2 \%=0.4$.

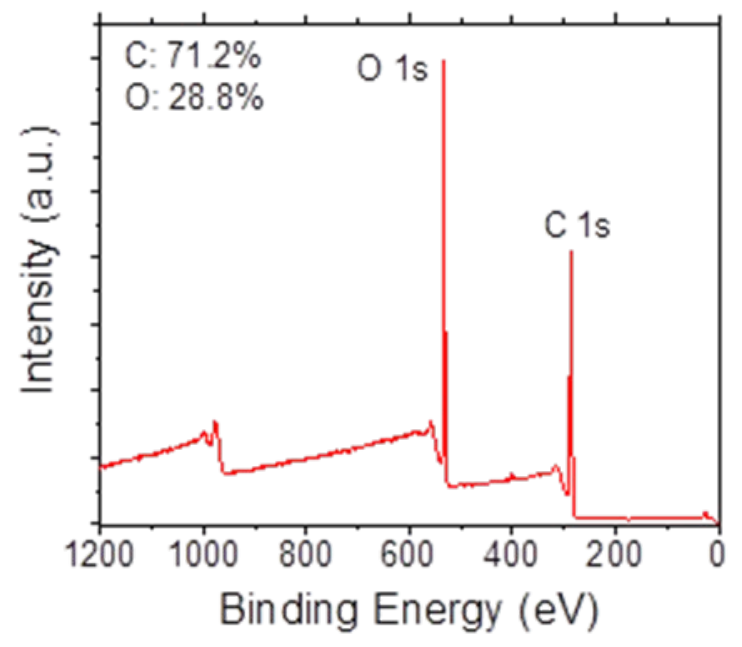

Figure S2. XPS survey spectrum of GO nanosheets. 


\section{Characterization of GO Charge in Aqueous Environment}

The zeta potential of GO was characterized in aqueous solutions of $100 \mathrm{mM} \mathrm{NaCl}$ at $\mathrm{pH}$ ranging from 2 to $12.100 \mathrm{mM} \mathrm{NaCl}$ was used to maintain a constant ionic strength so as to decouple the effects of ionic strength and $\mathrm{pH}$, considering the adjusting of the $\mathrm{pH}$ of the aqueous solution by adding $\mathrm{HCl}$ or $\mathrm{NaOH}$, which may increase the ionic strength of the solution, especially very acidic or basic solutions.

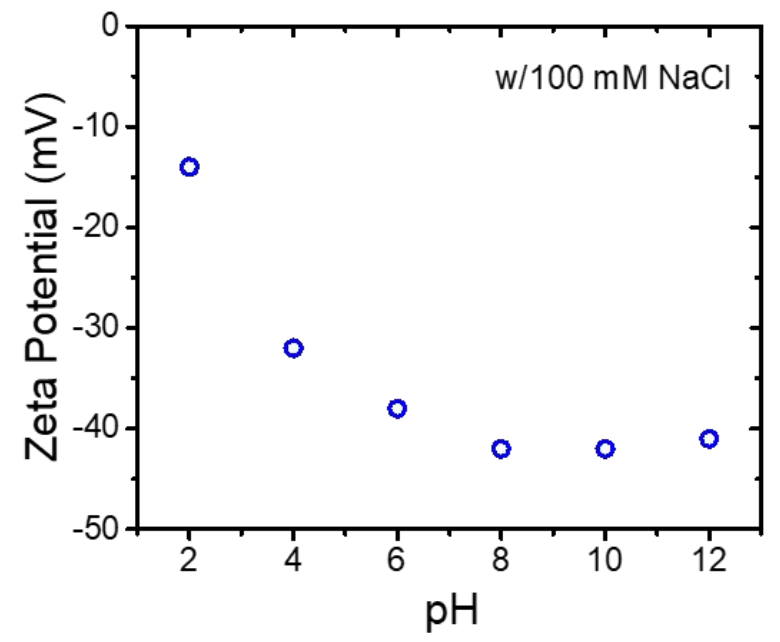

Figure S3. Charge of $\mathrm{GO}$ in $100 \mathrm{mM} \mathrm{NaCl}$ aqueous solution at different $\mathrm{pH}$ values.

\section{Characterization of GO charge in Organic Solvents}
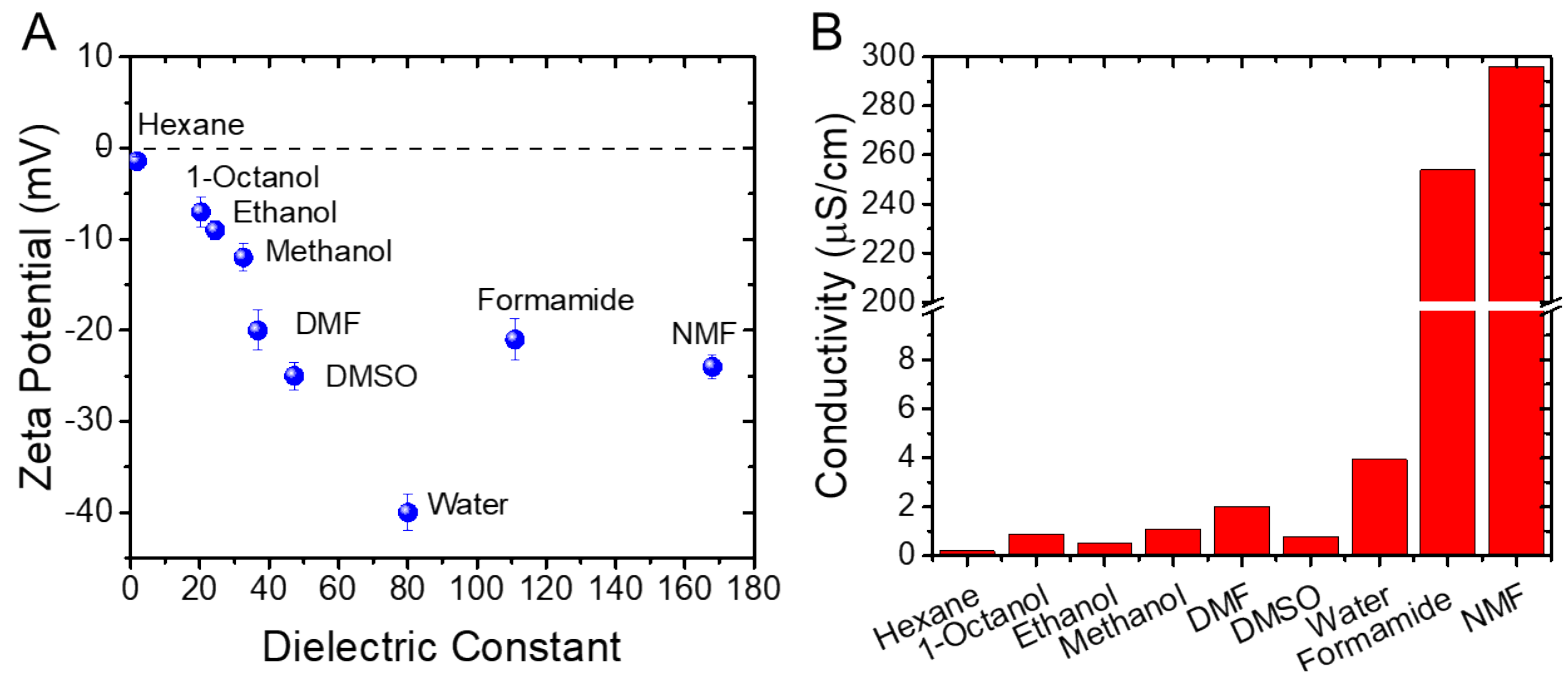

Figure S4. Charge of GO in representative organic solvents (A). Conductivity of representative organic solvents (B). 


\section{Measurement of the Contact Angle of Selected Solvents on a GO Membrane}

To obtain the equilibrium contact angle of the selected organic solvents on GO surface, a thin layer of $\mathrm{GO}(\sim 1 \mu \mathrm{m}$ thick) was drop-casted on a glass substrate to prevent the potential solvent permeation into the porous substrate used in GO membrane fabrication. As shown in Figure S5, GO could form a relatively smooth layer on the glass substrate, thus minimizing the influence of surface roughness on contact angle measurements. With an average roughness of around $36.9 \mathrm{~nm}$. the contact angle measured is believed to represent the intrinsic wettability of GO membrane.

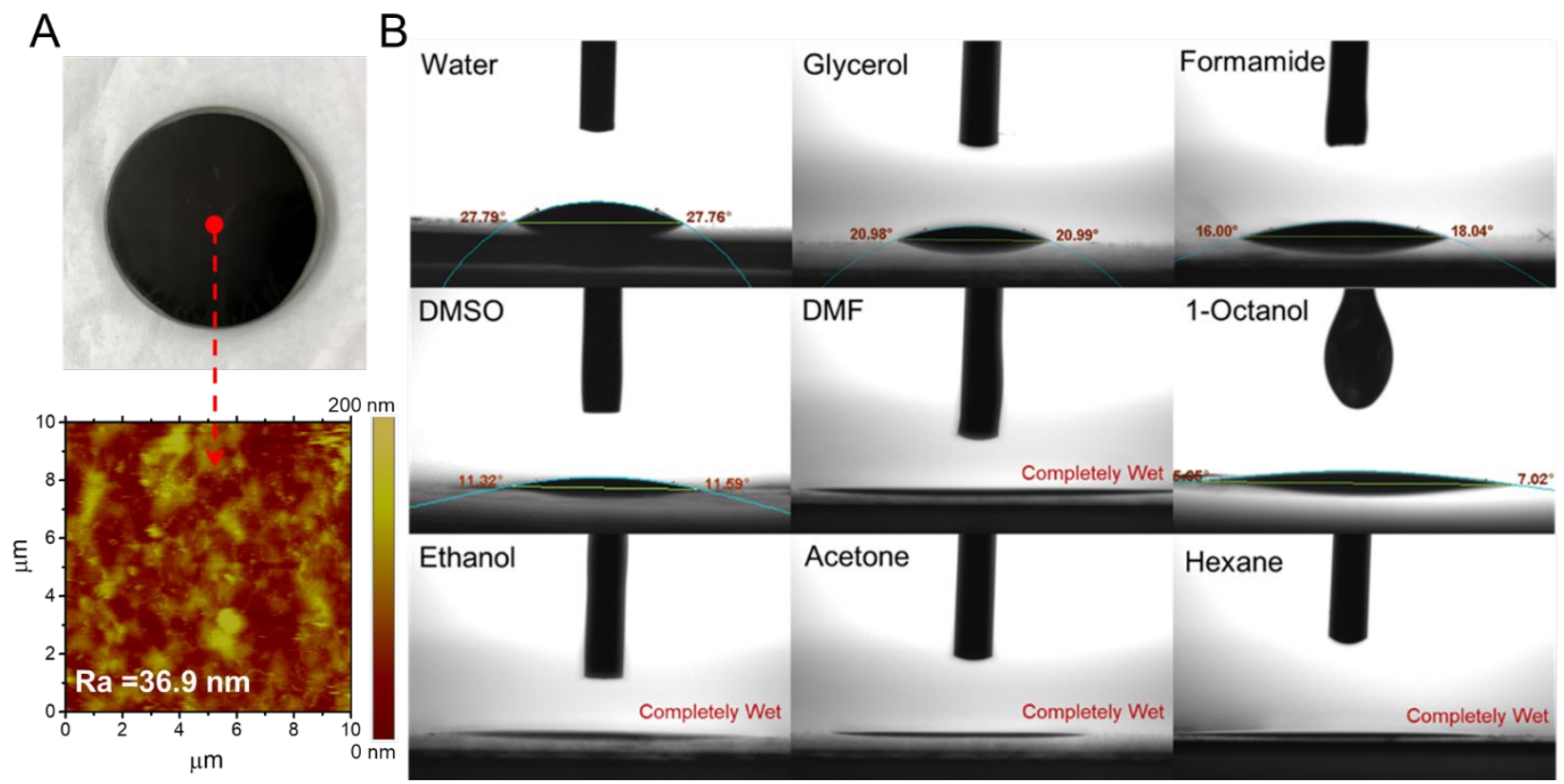

Figure S5. Optical and AFM image of GO surface on a glass substrate (A). The contact angle of selected solvents on GO membrane surfaces (B).

\section{Ellipsometry Measurement and Data Analysis}

The ellipsometer utilizes the polarized light reflected from the sample to model fit the complex refractive index $\tilde{n}$ and the thickness $\tau$ of the sample. In the present study, a multi-wavelength ellipsometer with a fixed incident angle was used. To model fit the $\tilde{n}$ and $\tau$, an optical model was built (Figure S6). For GO membranes in dry state, we used the n\&k model to fit the exact incident angle $\theta$ and $\tilde{n}_{0}$ of the substrate as the first layer. After the GO membrane was coated on the gold sensor, ellipsometry data were collected again. The distribution of $\tilde{n}_{1}$ for the GO layer was modeled using the re-parameterized 2-term Cauchy formula:

$$
n(\lambda)=n_{633 n m}+n_{\text {slope }}\left(\left(\frac{1000}{\lambda}\right)^{2}-\left(\frac{1000}{633}\right)^{2}\right)
$$

where $n(\lambda)$ is the refractive index at wavelength $\lambda, n_{\text {slope }}$ is the slope of the refractive index, and $\lambda$ is the incident wavelength (nm). With the calculated refractive index, the film thickness $\tau$ can now be obtained by model fitting the ellipsometry data. For the GO membrane in various solvents, $\tilde{n}_{2}$ of the solvents was adopted from the literature ${ }^{1}$. The obtained $\tilde{n}_{2}$ was then used as the third layer 
on top of the GO membrane (i.e., the second layer) when modeling the thickness of GO membrane in the solvents.

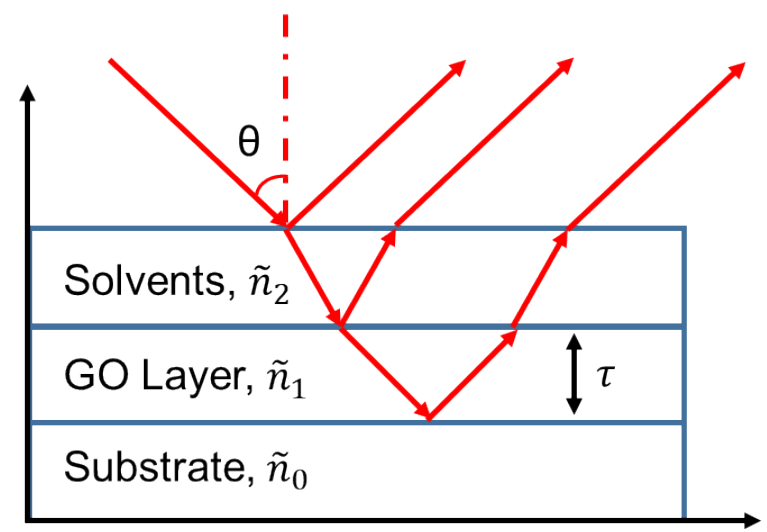

Figure S6. Schematic illustration of the optical model and fitting parameters for ellipsometry.

\section{Correlation of the Interlayer Spacing of GO with Dielectric Constant}

The dielectric constant of each selected solvent was obtained from the literature and correlated with the equilibrium interlayer spacing of GO in these solvents. According to the DLVO theory, the interlayer spacing of GO membrane would be linearly proportional to the square root of the dielectric constant, i.e., $\sqrt{\varepsilon_{s}}$. However, as shown in Figure S7, a flattened S-shaped curve is observed, indicating that the DLVO theory may not be applicable for the prediction of the interlayer spacing of GO in organic solvents.

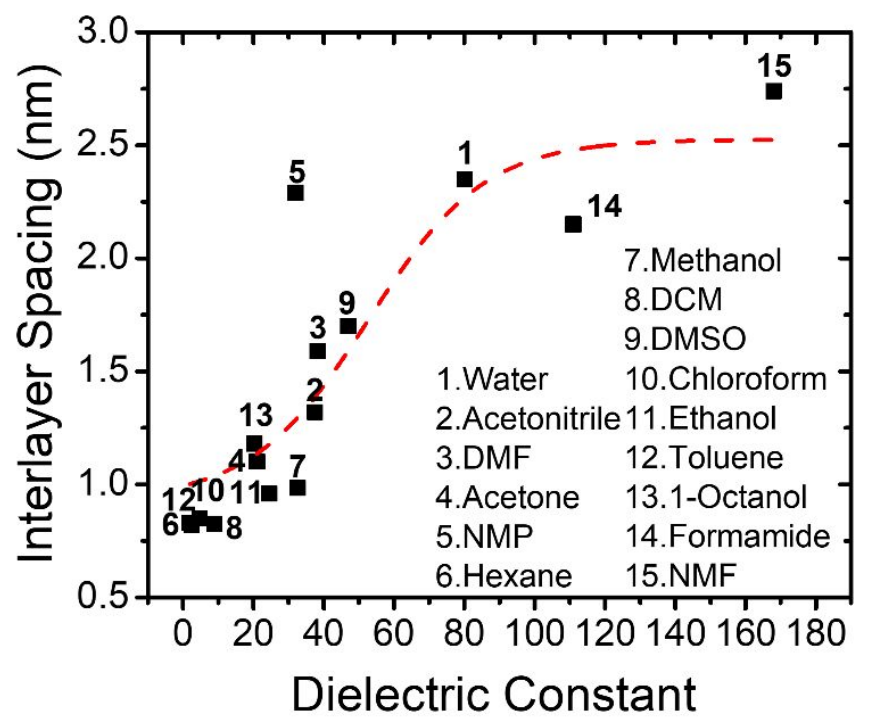

Figure S7. Correlation between the interlayer spacing of GO in solvents and their dielectric constant. 
Table S1. Solubility parameters and dipole moment of selected solvents

\begin{tabular}{lccccc} 
Solvents & $\begin{array}{c}\text { Dipole } \\
\text { Moment }\end{array}$ & $\begin{array}{c}\boldsymbol{\delta}_{\text {Hilderband }} \\
\mathbf{M P a}^{\mathbf{1 / 2}}\end{array}$ & $\begin{array}{c}\boldsymbol{\delta} \boldsymbol{D}, \\
\mathbf{M P a}^{\mathbf{1 / 2}}\end{array}$ & $\begin{array}{c}\boldsymbol{\delta} \boldsymbol{P} \\
\mathbf{M P a}^{\mathbf{1} / 2}\end{array}$ & $\begin{array}{c}\boldsymbol{\delta} \boldsymbol{H} \\
\mathbf{M P a}^{\mathbf{1} / 2}\end{array}$ \\
\hline Hexane & 0.08 & 14.1 & 14.1 & 0 & 0 \\
Toluene & 0.62 & 18.2 & 18 & 1.4 & 2 \\
Chloroform & 1.04 & 18.9 & 17.8 & 3.1 & 5.7 \\
Acetone & 2.88 & 19.9 & 15.5 & 10.4 & 7 \\
Dichloromethane & 1.6 & 20.2 & 18.2 & 6.3 & 6.1 \\
1-Octanol & 1.76 & 21.1 & 15.2 & 7.7 & 12.4 \\
N-Methyl-2-pyrrolidone (NMP) & 4.1 & 23.0 & 18 & 12.3 & 7.2 \\
Acetonenitrile & 3.93 & 24.4 & 15.3 & 18 & 6.1 \\
N,N-Dimethylformamide (DMF) & 3.82 & 24.9 & 17.4 & 13.7 & 11.3 \\
Ethanol & 1.69 & 26.5 & 15.8 & 8.8 & 19.4 \\
Dimethyl sulfoxide (DMSO) & 3.96 & 26.7 & 18.4 & 16.4 & 10.2 \\
Methanol & 1.7 & 29.6 & 15.1 & 12.3 & 22.3 \\
Water & 1.85 & 30.1 & 18.1 & 17.1 & 16.9 \\
N-Methylformamide & 3.83 & 30.1 & 17.4 & 18.8 & 15.9 \\
Formamide & 3.73 & 36.7 & 17.2 & 26.2 & 19
\end{tabular}

\section{Contributions of Intermolecular Interactions to the Solubility of GO}

For visual convenience, the 3D Hansen space can be easily translated into a 2D ternary plot. Solvents that share similar properties are close to each other in the plot. Solvents with high solubility of GO have large dipole moment and the ability to form H-bond.

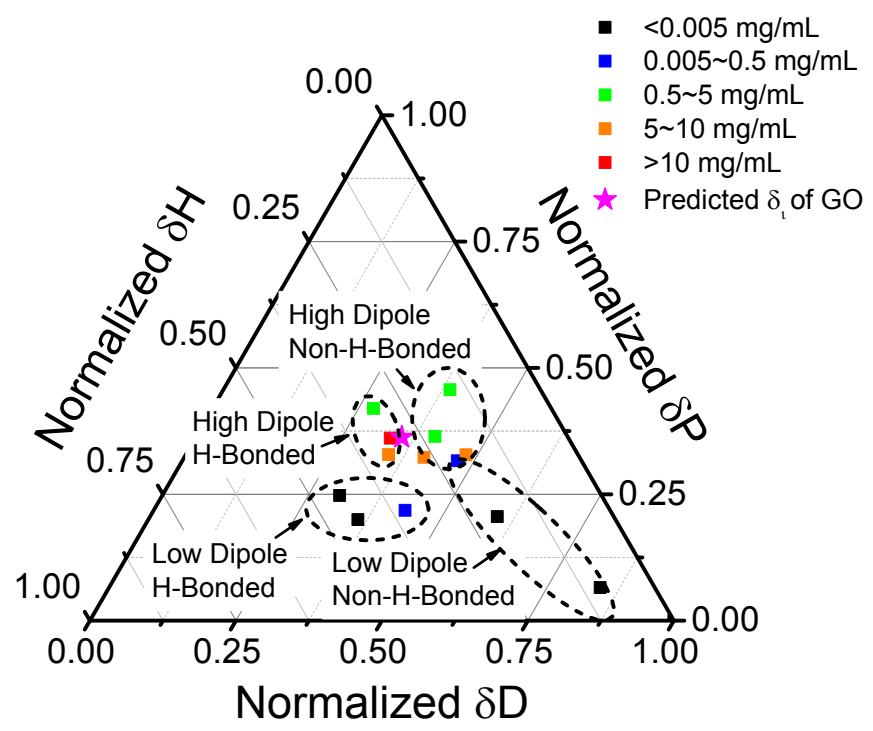

Figure S8. 2D plot of the Hansen solubility parameters of GO and solvents. 


\section{Integrity of GO Membranes in Selected Solvents}

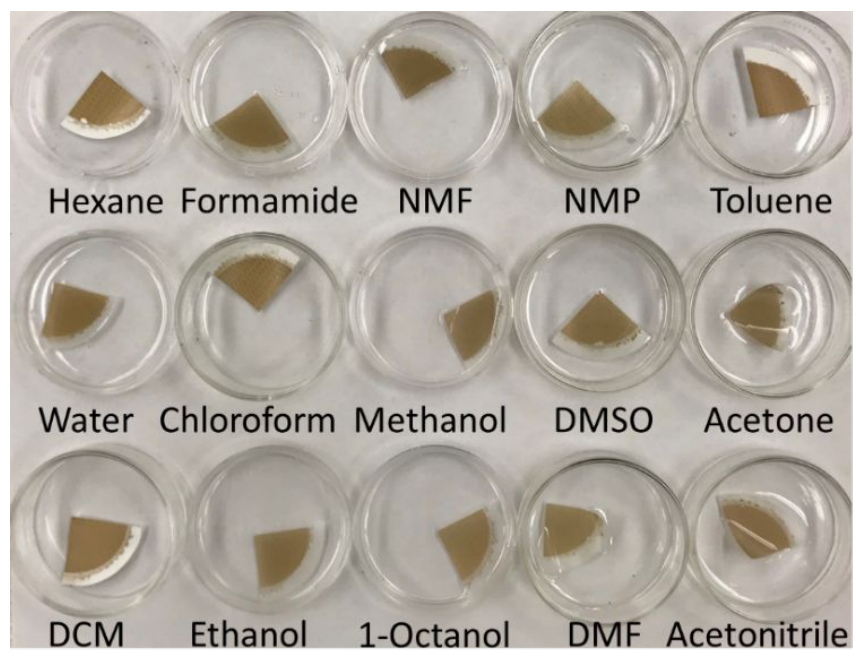

Figure S9. Photographs of GO membranes after soaking in solvents for 12 hours.

\section{Molecular Dynamics (MD) Simulation}

Two GO nanosheets are randomly decorated with oxygenated functional groups on both sizes. GO nanosheets are wrinkled because of the uneven distribution of functional groups on the surface, which is consistent with experimental findings. The model box has a size of $10 \mathrm{~nm} \times 10 \mathrm{~nm} \times 10 \mathrm{~nm}$, and is filled with each of the five different solvents, including water, ethanol $\left(\mathrm{C}_{2} \mathrm{H}_{6} \mathrm{O}\right)$, acetone $\left(\mathrm{C}_{3} \mathrm{H}_{6} \mathrm{O}\right)$, DMF $\left(\mathrm{NN}\right.$-dimethylformamide, $\left.\mathrm{C}_{3} \mathrm{H}_{7} \mathrm{NO}\right)$ and $\mathrm{NMF}(\mathrm{N}-$ methylformamide, $\mathrm{C}_{2} \mathrm{H}_{5} \mathrm{NO}$ ).

MD simulations were performed using GROMACS ${ }^{2}$. The simulation results were processed and visualized by VMD. ${ }^{3}$ The OPLS force fields, ${ }^{4}$ which are well optimized for simulating fluid problems, were used to model the GO membrane as well as ions and different solvents. The force model is expressed as:

$$
\begin{gathered}
\mathrm{V}=\sum_{\text {bonds }} k_{b}\left(b-b_{0}\right)^{2}+\sum_{\text {angles }} k_{\theta}\left(\theta-\theta_{0}\right)^{2}+\sum_{\text {dih }} k_{\phi}[1+\cos (n \phi-\delta)] \\
+\sum_{\text {imp }} k_{w}\left(w-w_{0}\right)^{2}+\sum_{\text {nobond }} \epsilon\left[\left(\frac{\sigma}{r}\right)^{12}-\left(\frac{\sigma}{r}\right)^{6}\right]+\frac{q_{i} q_{j}}{\epsilon_{0} r_{i j}}
\end{gathered}
$$

where the terms in the equation accounts for the energy due to bond stretches $\left(\mathrm{V}_{\text {bond }}\right)$, bond angle $\left(\mathrm{V}_{\text {angle }}\right)$, torsion angle $\left(\mathrm{V}_{\text {dih }}\right)$, out of plane bending $\left(\mathrm{V}_{\text {imp }}\right)$, van der Waals energy, and the electrostatic energy, respectively.

To eliminate surface effects and ensure a continuous flow of ions and water molecules, periodic boundary conditions in all three dimensions were imposed. The SPC/E model ${ }^{5}$ was employed to describe water molecules. The simulation was carried out with a time step of 2 fs. Each system was simulated for $5 \mathrm{~ns}$ followed by an equilibration under the NVT ensemble (constant number of atoms, fixed volume, and constant temperature of $298 \mathrm{~K}$ ). The Nose-Hoover 
thermostat ${ }^{6}$ was used to maintain the temperature at $298 \mathrm{~K}$. A non-equilibrium MD simulation was performed ${ }^{7}$ by adding constant acceleration in one direction to each atom. The PME (Particlemesh Ewald) method was employed to accurately account for the long-range electrostatic interactions of the charges or ions and their periodic images. The cut-off of the Lennard-Jones (LJ) interactions was set at $1.2 \mathrm{~nm}$ in each direction.

\section{Composition of Oxygenated Functional Groups on GO Nanosheets}

To better determine the chemical structural of GO, the $\mathrm{O}$ 1s peak characterized by XPS was deconvoluted. As shown in Figure S10, the carboxyl/carbonyl groups, epoxide groups, and hydroxyl groups account for $20 \%, 47 \%$, and $33 \%$, respectively, of the oxygenated functional groups.

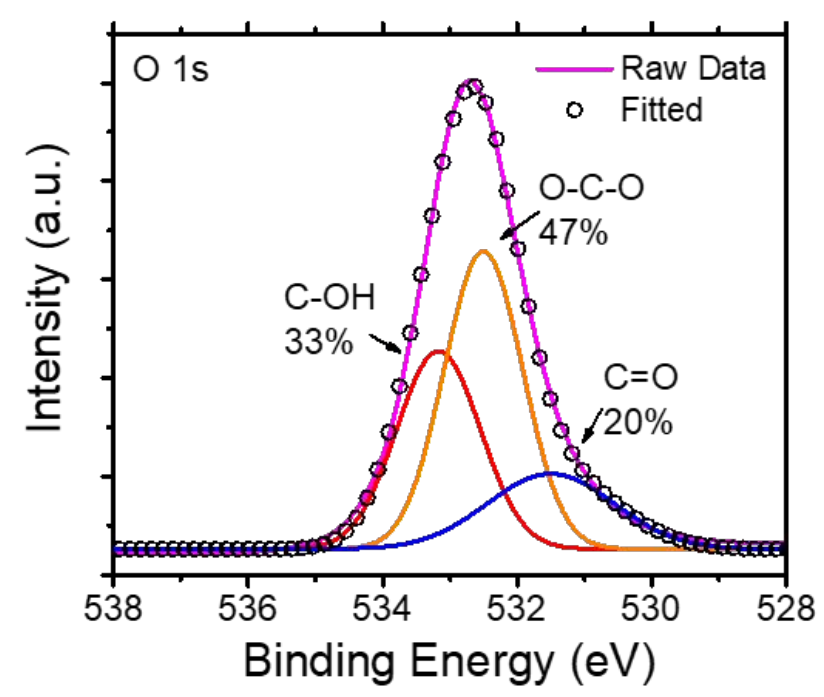

Figure S10. XPS spectra of O 1s peak

\section{Partitioning of Dye Molecules into GO Membranes}

To evaluate the role of partitioning in the separation performance of GO membrane, we measured the partitioning of RB into GO membranes from a few selected solvents. Briefly, 10 ppm RB was first dissolved in water, DMF, ethanol and acetone, and each solution was filtered through a $\sim 100$ $\mathrm{nm}$ thick GO membrane prepared by depositing $0.35 \mathrm{mg}$ GO on a nylon membrane substrate. Excessive amount of solution was filtered through the GO membrane to achieve equilibrium in partitioning. When the partitioning reaches equilibrium, the concentration of $\mathrm{RB}$ in feed $\left(C_{F}\right)$ and permeate $\left(C_{P}\right)$ were measured to determine the mass of RB partitioned into the GO membrane using a mass balance. As shown in Figure S11, the GO membrane extracts significantly more RB from water than from organic solvents. The color of GO membrane evidently turned pinkish in water, while the pinkish color in organic solvents was much weaker. The low partition in organic solvents indicates that the electrostatic interactions between $\mathrm{GO}$ and RB are weaker in organic solvents than in water. 


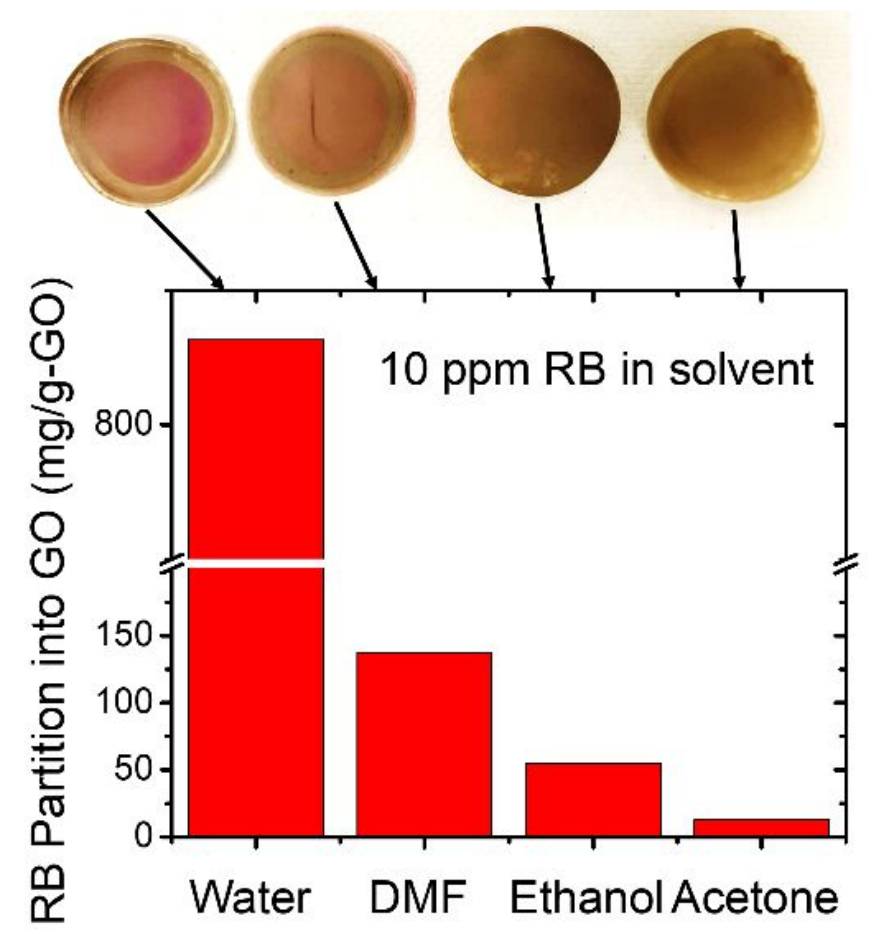

Figure S11. Adsorption of Rhodamine B (RB) onto GO membrane. Optical images on the top show the color change of the GO membrane surface after the adsorption of RB in each solvent.

Solubility of Rhodamine B and Methylene Blue in Organic Solvents

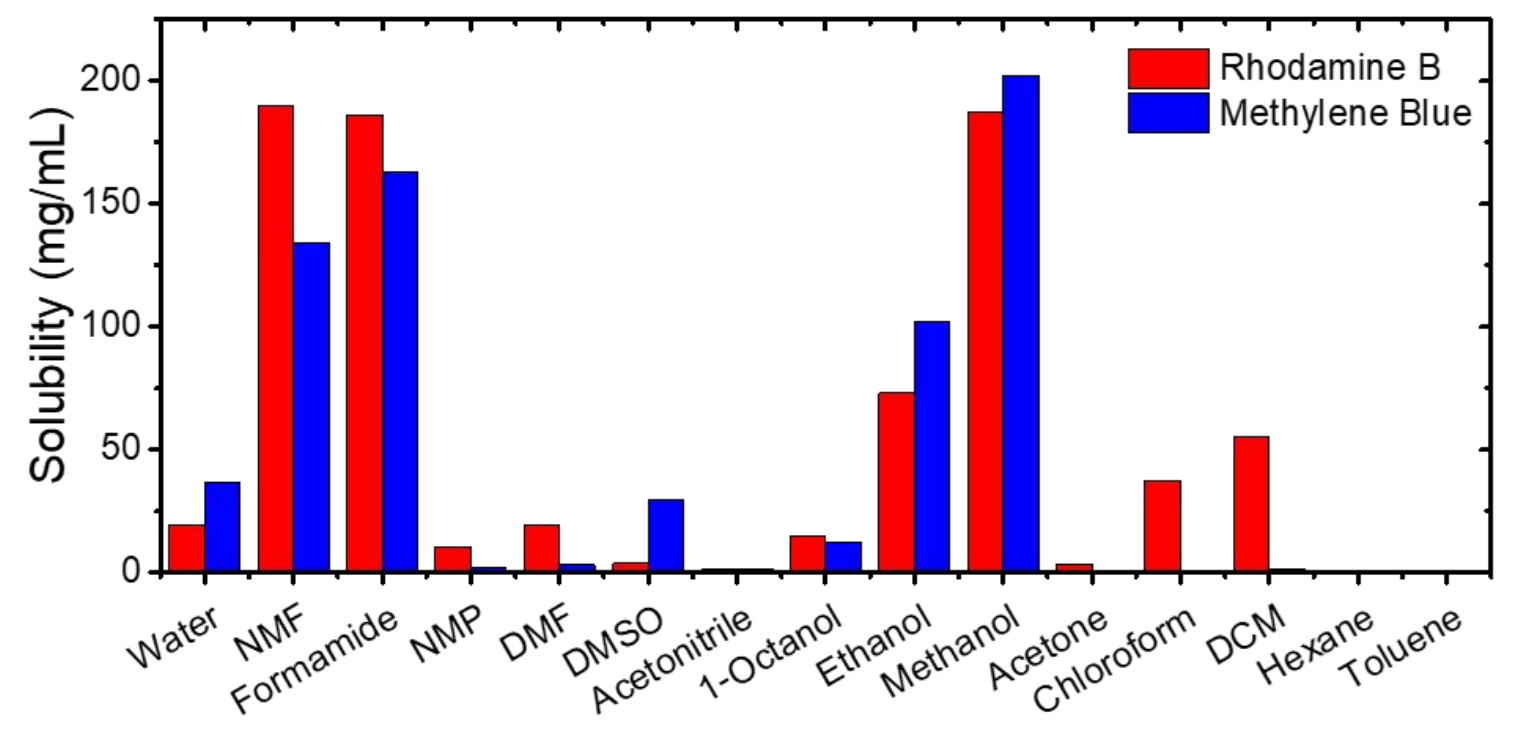

Figure S12. Solubility of rhodamine B and methylene blue in organic solvents. 
Table S2. Comparison of the membrane performance for organic solvent nanofiltration (OSN)

\begin{tabular}{|c|c|c|c|c|c|c|c|}
\hline $\begin{array}{c}\text { Membrane } \\
\text { Type }\end{array}$ & $\begin{array}{c}\text { Membrane } \\
\text { Material }\end{array}$ & Solvent & Solute & $\begin{array}{l}\text { Solute } \\
\text { MW I }\end{array}$ & $\begin{array}{c}\text { Flux } \\
\text { LMH/bar }\end{array}$ & $\begin{array}{c}\text { Rejection } \\
\%\end{array}$ & Ref \\
\hline \multirow{3}{*}{ Polymer } & $\mathrm{CA}$ & EtOH & Bromothymol Blue & 624 & 0.4 & 82 & 8 \\
\hline & Cross-linked PI & $\mathrm{EtOH}$ & Azobenzene & 182 & 0.06 & 41 & 9 \\
\hline & PBI & $\mathrm{EtOH}$ & Brilliant Blue & 826 & 3.7 & 99 & 10 \\
\hline \multirow[t]{2}{*}{ MMM } & CA/Gold NP & $\mathrm{EtOH}$ & Bromothymol Blue & 624 & 1.5 & 82 & 8 \\
\hline & PI/Gold NP & $\mathrm{EtOH}$ & Bromothymol Blue & 624 & 2.9 & 82 & 11 \\
\hline ceramic & $\mathrm{SiO} 2 / \mathrm{ZrO} 2$ & $\mathrm{EtOH}$ & N-hexane & 86 & 0.003 & 40 & 12 \\
\hline \multicolumn{8}{|c|}{ 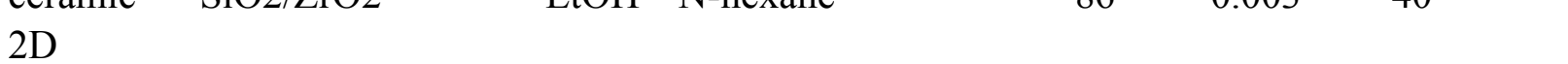 } \\
\hline Material & Shear-align GO & EtOH & Rhodamine B & 479 & 180 & 45 & 13 \\
\hline This work & Layer-stacked GO & EtOH & Methylene Blue & 479 & 2.25 & 85 & \\
\hline \multirow[t]{3}{*}{ Polymer } & $\begin{array}{l}\text { Cross-linked PI } \\
\text { Cross-linked }\end{array}$ & Acetone & Azobenzene & 180 & 0.3 & 99 & 9 \\
\hline & PANI & Acetone & Styrene Oligomer & $236-1200$ & 1.4 & 99 & 14 \\
\hline & Cross-linked PBI & Acetone & Styrene Oligomer & $236-1200$ & 15.6 & 80 & 14 \\
\hline \multirow[t]{2}{*}{ MMM } & APTMS/PI & Acetone & Styrene Oligomer & $236-1200$ & 7.5 & 95 & 15 \\
\hline & Polymer NP/PI & Acetone & Styrene Oligomer & $236-1200$ & 1.3 & 90 & 16 \\
\hline ceramic & TiO2/alumina & Acetone & Erythrosine B & 880 & 0.4 & 97 & 17 \\
\hline This work & $\begin{array}{l}\text { Layer-stacked } \\
\mathrm{GO}\end{array}$ & Acetone & Methylene Blue & 479 & 9.44 & 98 & \\
\hline \multirow[t]{6}{*}{ Polymer } & $\mathrm{PA} / \mathrm{PP}$ & Methanol & Brilliant Blue R & 826 & 0.15 & 88 & 18 \\
\hline & Crosslinked PANI & Methanol & Styrene Oligomer & $236-1200$ & 0.8 & 100 & 14 \\
\hline & PPSF & Methanol & Rose Bengal & 1017 & 0.4 & 88 & 19 \\
\hline & PPSF/PI & Methanol & Sudan II & 276 & 2 & 95 & 20 \\
\hline & VAPEEK & Methanol & Rose Bengal & 1017 & 0.2 & 90 & 21 \\
\hline & Inopor & & & & & & \\
\hline ceramic & TiO2/alumina & Methanol & Victoria Blue & 506 & 0.4 & 99 & 17 \\
\hline & & & & & & & \\
\hline Material & Crosslinked GO & Methanol & I Evans Blue & 960 & 1.8 & 92 & 22 \\
\hline This work & $\begin{array}{l}\text { Layer-stacked } \\
\text { GO }\end{array}$ & Methanol & Methylene Blue & 479 & 3.29 & 80.4 & \\
\hline \multirow[t]{4}{*}{ Polymer } & Cross-linked PI & DMF & Styrene Oligomer & $236-1200$ & 1.6 & 95 & 23 \\
\hline & Cross-linked & & & & & & \\
\hline & PANI & DMF & Styrene Oligomer & $236-1200$ & 0.6 & 95 & 14 \\
\hline & $\begin{array}{l}\text { Cross-linked PBI } \\
\text { Cross-linked }\end{array}$ & DMF & Styrene Oligomer & $236-1200$ & 0.4 & 99 & 24 \\
\hline MMM & $\mathrm{PI} / \mathrm{TiO} 2$ & DMF & Styrene Oligomer & $236-1200$ & 2.1 & 90 & 25 \\
\hline This work & $\begin{array}{l}\text { Layer-stacked } \\
\text { GO }\end{array}$ & DMF & Methylene Blue & 479 & 5.82 & 32.1 & \\
\hline
\end{tabular}




\section{References}

1. $\quad$ Saunders, J. E.; Sanders, C.; Chen, H.; Loock, H. P., Refractive Indices of Common Solvents and Solutions at $1550 \mathrm{~nm}$. Appl. Opt. 2016, 55, 947-953.

2. $\quad$ Berendsen, H. J. C.; Vanderspoel, D.; Vandrunen, R., GROMACS: A Message-Passing Parallel Molecular Dynamics Implementation Comput. Phys. Commun. 1995, 91, 43-56.

3. Humphrey, W.; Dalke, A.; Schulten, K., VMD: Visual Molecular Dynamics. J. Mol. Graphics 1996, 14, 33-38.

4. Jorgensen, W. L.; Tirado-Rives, J., The OPLS [Optimized Potentials for Liquid Simulations] Potential Functions for Proteins, Energy Minimizations for Crystals of Cyclic Peptides and Crambin. J. Am. Chem. Soc. 1988, 110, 1657-1666.

5. Berendsen, H.; Grigera, J.; Straatsma, T., The Missing Term in Effective Pair Potentials. J. Phys. Chem. 1987, 91, 6269-6271.

6. Nosé, S., A Unified Formulation of The Constant Temperature Molecular Dynamics Methods. J. Chem. Phys. 1984, 81, 511-519.

7. Hoover, W. G.; Hoover, C., Nonequilibrium Molecular Dynamics. Condens. Matter Phys. 2005, 8,42 .

8. Vanherck, K.; Hermans, S.; Verbiest, T.; Vankelecom, I., Using the Photothermal Effect to Improve Membrane Separations via Localized Heating. J. Mater. Chem. 2011, 21, 6079-6087.

9. Karan, S.; Samitsu, S.; Peng, X.; Kurashima, K.; Ichinose, I., Ultrafast Viscous Permeation of Organic Solvents through Diamond-Like Carbon Nanosheets. Science 2012, 335, 444-447.

10. Xing, D. Y.; Chan, S. Y.; Chung, T. S., The Ionic Liquid EMIM OAc As a Solvent to Fabricate Stable Polybenzimidazole Membranes for Organic Solvent Nanofiltration. Green Chem. 2014, 16, 1383-1392.

11. Vanherck, K.; Vankelecom, I.; Verbiest, T., Improving Fluxes of Polyimide Membranes Containing Gold Nanoparticles by Photothermal Heating. J. Membr. Sci. 2011, 373, 5-13.

12. Tsuru, T.; Miyawaki, M.; Kondo, H.; Yoshioka, T.; Asaeda, M., Inorganic Porous Membranes for Nanofiltration of Nonaqueous Solutions. Sep. Purif. Technol. 2003, 32, 105-109. 13. Akbari, A.; Meragawi, S. E.; Martin, S. T.; Corry, B.; Shamsaei, E.; Easton, C. D.; Bhattacharyya, D.; Majumder, M., Solvent Transport Behavior of Shear Aligned Graphene Oxide Membranes and Implications in Organic Solvent Nanofiltration. ACS Appl. Mater. Interfaces 2018, 10, 2067-2074.

14. Loh, X. X.; Sairam, M.; Bismarck, A.; Steinke, J. H. G.; Livingston, A. G.; Li, K., Crosslinked Integrally Skinned Asymmetric Polyaniline Membranes for Use in Organic Solvents. J. Membr. Sci. 2009, 326, 635-642.

15. Siddique, H.; Rundquist, E.; Bhole, Y.; Peeva, L. G.; Livingston, A. G., Mixed Matrix Membranes for Organic Solvent Nanofiltration. J. Membr. Sci. 2014, 452, 354-366.

16. Siddique, H.; Peeva, L. G.; Stoikos, K.; Pasparakis, G.; Vamvakaki, M.; Livingston, A. G., Membranes for Organic Solvent Nanofiltration Based on Preassembled Nanoparticles. Ind. Eng. Chem. 2013, 52, 1109-1121.

17. Geens, J.; Boussu, K.; Vandecasteele, C.; Van der Bruggen, B., Modelling of Solute Transport in Non-Aqueous Nanofiltration. J. Membr. Sci. 2006, 281, 139-148.

18. Kosaraju, P. B.; Sirkar, K. K., Interfacially Polymerized Thin Film Composite Membranes 
on Microporous Polypropylene Supports for Solvent-Resistant Nanofiltration. J. Membr. Sci. 2008, 321, 155-161.

19. Darvishmanesh, S.; Jansen, J. C.; Tasselli, F.; Tocci, E.; Luis, P.; Degreve, J.; Drioli, E.; Van der Bruggen, B., Novel Polyphenylsulfone Membrane for Potential Use in Solvent Nanofiltration. J. Membr. Sci. 2011, 379, 60-68.

20. Jansen, J. C.; Darvishmanesh, S.; Tasselli, F.; Bazzarelli, F.; Bernardo, P.; Tocci, E.; Friess, K.; Randova, A.; Drioli, E.; Van der Bruggen, B., Influence of the Blend Composition on the Properties and Separation Performance of Novel Solvent Resistant Polyphenylsulfone/Polyimide Nanofiltration Membranes. J. Membr. Sci. 2013, 447, 107-118.

21. Hendrix, K.; Van Eynde, M.; Koeckelberghs, G.; Vankelecom, I. F. J., Crosslinking of Modified Poly(Ether Ether Ketone) Membranes for Use in Solvent Resistant Nanofiltration. $J$. Membr. Sci. 2013, 447, 212-221.

22. Gao, T. T.; Wu, H. B.; Tao, L.; Qu, L. T.; Li, C., Enhanced Stability and Separation Efficiency of Graphene Oxide Membranes in Organic Solvent Nanofiltration. J. Mater. Chem. A 2018, 6, 19563-19569.

23. See-Toh, Y. H.; Silva, M.; Livingston, A., Controlling Molecular Weight Cut-Off Curves for Highly Solvent Stable Organic Solvent Nanofiltration (OSN) Membranes. J. Membr. Sci. 2008, 324, 220-232.

24. Valtcheva, I. B.; Kumbharkar, S. C.; Kim, J. F.; Bhole, Y.; Livingston, A. G., Beyond Polyimide: Crosslinked Polybenzimidazole Membranes for Organic Solvent Nanofiltration (OSN) in Harsh Environments. J. Membr. Sci. 2014, 457, 62-72.

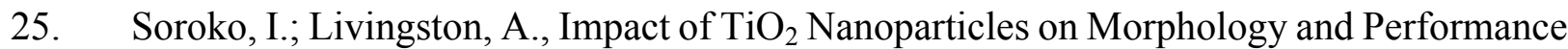
of Crosslinked Polyimide Organic Solvent Nanofiltration (OSN) Membranes. J. Membr. Sci. 2009, 343, 189-198. 